\title{
ФИЗИRO-MATEMATИYECRИE HAYRИ
}

УДК 53.09

\section{ВЫСОКОВОЛЬТНАЯ ЭЛЕКТРОПРОВОДНОСТЬ И РЕЛАКСАЦИОННЫЕ ПРОЦЕССЫ В БИНАРНЫХ СМЕСЯХ ДИГИДРОФОСФАТОВ РУБИДИЯ И ЦЕЗИЯ.}

DOI: $10.31618 /$ ESU.2413-9335.2019.5.69.502

Гаджиев Синдибад Магомедович

профессор, д.х.н.,

Дагестанский государственньй университет;

Дагестанский государственный университет народного хозяйства,

2. Махачкала

\begin{abstract}
АННОТАЦИЯ
Исследованы зависимость электропроводности от напряженности электрического поля и релаксационные процессы в бинарных смесях протонных твердых электролитов $\mathrm{Rb}, \mathrm{Cs} / \mathrm{H}_{2} \mathrm{PO}_{4}$ при 520 К. C ростом напряженности электрического поля электропроводность электролита увеличивается, стремясь к предельному значению. Наибольший относительный рост проводимости обнаружен у состава $0.5 \mathrm{Rb}, 0.5 \mathrm{Cs} / \mathrm{H}_{2} \mathrm{PO}_{4}$ и составляет $208 \%$ при напряженности поля $1,5 \mathrm{MB} / \mathrm{M}$. Время релаксации имеет порядок $10^{4}-10^{5} \mathrm{c}$.
\end{abstract}

ABSTRACT

The dependence of the electrical conductivity on the electric field strength and relaxation processes in binary mixtures of proton solid electrolytes $\mathrm{Rb}, \mathrm{Cs} / \mathrm{H}_{4} \mathrm{PO}_{4}$ at $520 \mathrm{~K}$ was studied. With increasing electric field strength, the electrolyte conductivity increases, tending to the limiting value. The largest relative increase in conductivity was found for the composition $0.5 \mathrm{Rb}, 0.5 \mathrm{Cs} / \mathrm{H}_{2} \mathrm{PO}_{4}$ and amounted to $208 \%$ at a field strength of $1.5 \mathrm{MV} / \mathrm{m}$. The relaxation time is of the order of $10^{4}-10^{5} \mathrm{~s}$.

Ключевые слова: протонный твердый электролит; фосфаты; бинарные смеси; электропроводность; высоковольтный импульсный разряд; пробой; активация; релаксация.

Keywords: proton solid electrolyte; phosphates; binary mixtures; electrical conductivity; high voltage pulse discharge; breakdown; activation; relaxation.

Протонные твердые электролиты (ПТЭ) обладают высокой униполярной проводимостью по протону. Благодаря этому они используются как: датчики парциального давления газов; реакторы (де)гидрирования углеводородов; электрохромные дисплеи; водородные насосы; электрохимические аккумуляторы; электролизеры для получения водорода и т.д. [1]. Дигидрофосфаты рубидия и цезия благодаря сегнетоэлектрическим и пьезоэлектрическим свойствам используются в качестве электрооптических модуляторов. С их помощью осуществляется быстрый поворот пучка световых лучей под действием электрического тока, и они предпочтительнее обычной ячейки Кeppa.

Исследование высоковольтного поведения индивидуальных протонных твердых электролитов (ПТЭ) $\mathrm{RbH}_{2} \mathrm{PO}_{4}$ и $\mathrm{CsH}_{2} \mathrm{PO}_{4}$ [2,3] показало, что с ростом напряженности электрического поля их электропроводность возрастает и стремится к насыщению. Относительный рост проводимости в них до пробойных явлений доходит до 180 и более \%. Экспериментальное исследование поведения бинарных систем ПТЭ и их расплавов в сильных электрических полях представляет больший интерес, чем индивидуальные электролиты. Это объясняется тем, что: во-первых, композитные электролиты в большинстве случаях обладают большей ионной проводимостью, чем индивидуальные вещества, составляющие композит; во-вторых, при образовании композита значительно снижается температурная область существования высокопроводящей фазы. Снижение температуры существования твердой высокопроводящей фазы (в нашем случае на 40 - 50 К) имеет немаловажное значение в целях экономии энергии при решении различных технологических задач, например, при создании химических источников тока резервного типа, при осуществлении генерации монохроматического света с перестраиваемой частотой и т.д.

Исследована

высоковольтная электропроводность бинарной системы твердого электролита $\mathrm{Rb}, \mathrm{Cs} / \mathrm{H}_{2} \mathrm{PO}_{4}$ различных составов от напряженности электрического поля (НЭП). Эксперименты проводились по методике, описанной в работах [2-4]. В экспериментах нами были использованы дигидрофосфаты рубидия и цезия марки ХЧ. Для освобождения от остатков воды соли медленно нагревались в вакууме до $100^{\circ}$ C. Сухие, размельченные порошки солей взвешивались на аналитических весах соответствующих составов по весу, тщательно перемешивались и засыпались в специальную цилиндрическую металлическую форму и ставились под пресс при давлении более 300 атм. и выдерживали в течение трех часов. Полученный таким образом твердый электролит толщиной около 2 мм помещался в специально изготовленную из фторопласта ячейку. 
Эксперименты показывают, что с ростом НЭП электропроводность электролитов возрастает и имеет тенденцию к насыщению. На рис.1 приведены зависимости относительного изменения проводимости индивидуальных и бинарных смесей дигидрофосфатов рубидия и цезия при 520 К до пробойных явлений. Данные для индивидуальных электролитов взяты из работ $[2,3]$.

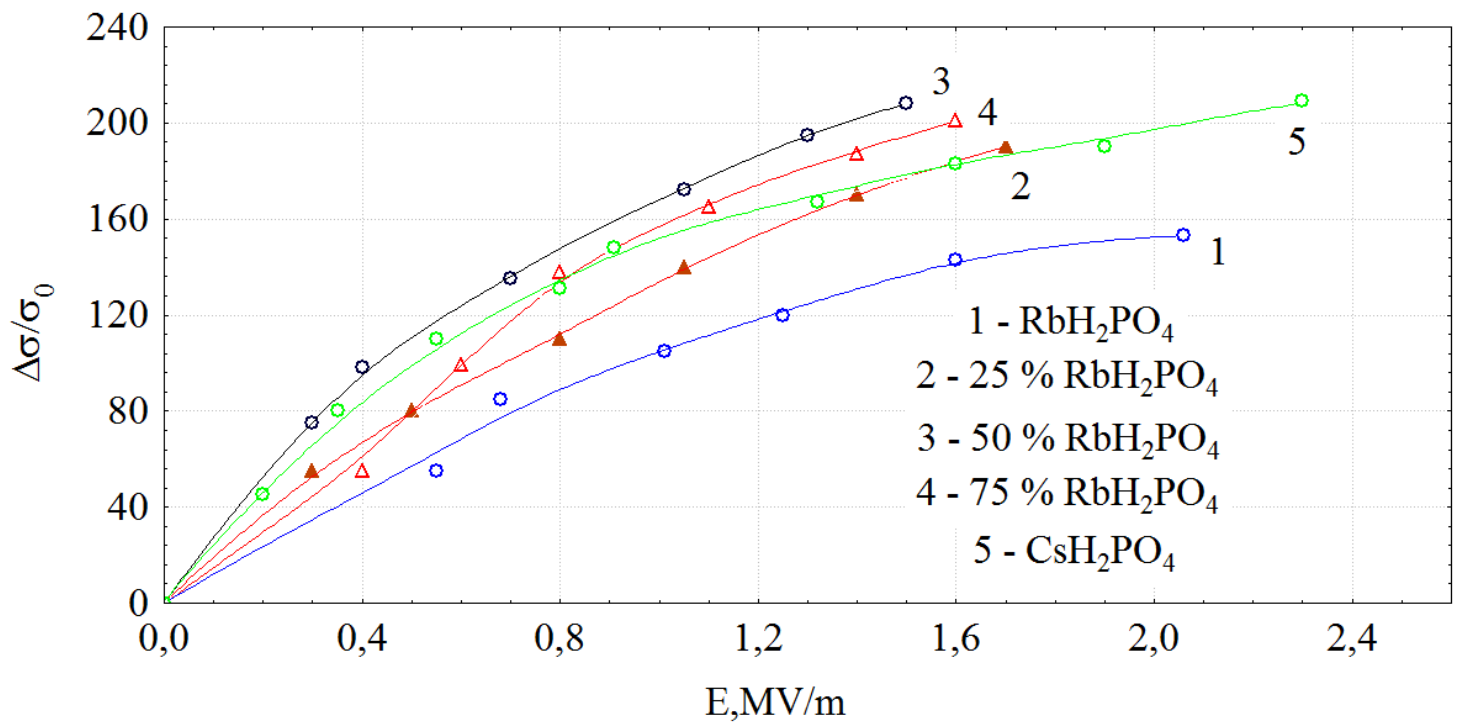

Pис.1. Зависимость относительного изменения проводимости бинарных смесей $\mathrm{Rb}, \mathrm{Cs} / \mathrm{H}_{2} \mathrm{PO}_{4} \mathrm{om}$ напряженности электрического поля при $520 \mathrm{~K}$.

Насыщение проводимости не удается достичь в связи пробоем электролитов. При одинаковых напряженностях полей наибольший относительный рост проводимости наблюдается у состава $0.5 \mathrm{Rb}, 0.5 \mathrm{Cs} / \mathrm{H}_{2} \mathrm{PO}_{4}$ и составляет $208 \%$ при $\mathrm{E}=1,5$
MB/м. При напряженностях полей более 1,2 MB/м у бинарных смесей относительный рост проводимости выше, чем у индивидуальных электролитов. Эти результаты приведены таблице 1. Рост проводимости ПТЭ нами учитывался до пробойных явлений.

Таблица 1

Высоковольтная электропроводность бинарных смесей дигидрофосфатов рубидия и цезия при 520 К.

\begin{tabular}{|c|c|c|c|c|c|}
\hline Состав & $\mathrm{E}, \mathrm{MB} / \mathrm{M}^{*}$ & $\sigma_{0}, \mathrm{~ms}$ & $\sigma_{E}, \mathrm{~ms}$ & $\frac{\Delta \sigma}{\sigma_{0}}, \%$ & Прим. \\
\hline $\mathrm{RbH}_{2} \mathrm{PO}_{4}$ & 2,06 & 1,351 & 3,417 & 153,1 & пробой \\
\hline $0,25 \mathrm{Rb} 0,75 \mathrm{Cs} / \mathrm{H}_{2} \mathrm{PO}_{4}$ & 1,70 & 1,520 & 4,408 & 190 & пробой \\
\hline $0,5 \mathrm{Rb} 0,5 \mathrm{Cs} / \mathrm{H}_{2} \mathrm{PO}_{4}$ & 1,50 & 1,671 & 5,147 & 208 & пробой \\
\hline $0,75 \mathrm{Rb} 0,25 \mathrm{Cs} / \mathrm{H}_{2} \mathrm{PO}_{4}$ & 1,59 & 1,540 & 4,635 & 201 & пробой \\
\hline $\mathrm{Cs} \mathrm{H}_{2} \mathrm{PO}_{4}$ & 2,30 & 1,43 & 4,419 & 209 & пробой \\
\hline
\end{tabular}

* - указаны напряженности полей, выше которых электролит пробивается

Состояние избыточной проводимости, как и во всех ранее исследованных электролитах, сохраняется длительное время (активация высоковольтными импульсными разрядами, так называемая ВИР-активация) постепенно уменьшаясь со временем. Эксперименты показывают, что уровень активации в бинарных системах протонных твердых электролитов дигидрофосфатов рубидия и цезия до пробойных явлений, в зависимости от состава, достигает 150 200\%, причем, она тем выше, чем выше амплитуда импульсного напряжения. Исследована динамика постактивационной релаксации избыточной проводимости бинарных систем $\mathrm{Rb}, \mathrm{Cs} / \mathrm{H}_{2} \mathrm{PO}_{4}$. Ha рис.2 на примере бинарной системы $0,5 \mathrm{Rb} 0,5 \mathrm{Cs} / \mathrm{H}_{2} \mathrm{PO}_{4}$ приведены релаксационные кривые после ВИР в координатах $\ln \left(\sigma / \sigma_{0}\right)$ - время.

Как видно, наибольшее изменение избыточной проводимости происходит в самом начале после ВИР. При больших амплитудах импульсного напряжения оно выражено более ярко. На этом участке релаксации явно наблюдается колебательный характер релаксации. Через $3-6$ мин (в зависимости от амплитуды напряжения) возвращение системы к равновесному состоянию происходит по экспоненциальному закону и подчиняется кинетическому уравнению первого порядка 
$\Delta \sigma=\Delta \sigma(0) \exp (-t / \tau)$ где $\Delta \sigma(0)$ - избыточная проводимость при $\mathrm{t}=0$, $\tau$ - время релаксации.

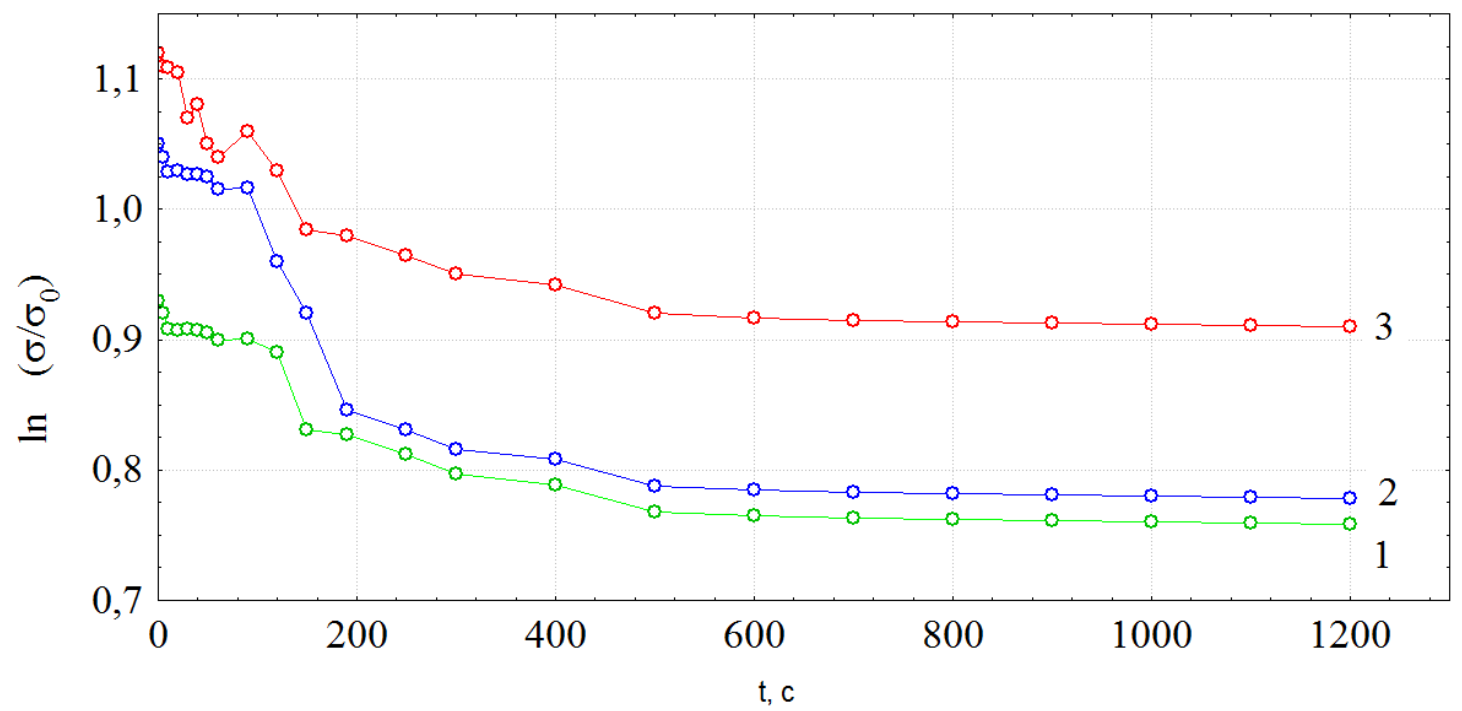

Pис.2. Изменение $\ln \left(\sigma / \sigma_{0}\right)$ во времени после высоковольтных разрядов в бинарной смеси 0,5Rb0,5Cs/ $\mathrm{H}_{2} \mathrm{PO}_{4}$ при амплитудах напряжения: $1-1,4 ; 2-2,1 ; 3-3,0 \kappa \mathrm{B}$

На линейном участке релаксационных кривых методом наименьших квадратов определено время жизни неравновесных носителей заряда (следует отметить, что на этом участке релаксационный процесс все же носит колебательный характер с уменьшающейся амплитуды флуктуаций). С точностью до 5,0 \% оно не зависело от амплитуды импульсного напряжения. Рассчитанные значения времен релаксации избыточной проводимости всех исследованных бинарных систем приведены в таблице 2. Эти результаты показывают, что во всех составах бинарных систем время релаксации избыточной проводимости больше, чем в индивидуальных электролитах. Следует отметить, что в электролите состава $0,5 \mathrm{Rb} 0,5 \mathrm{Cs} / \mathrm{H}_{2} \mathrm{PO}_{4}$ наблюдается как наибольшее относительное увеличение проводимости с полем, так и наибольшее время релаксации, достигающее почти $10^{5} \mathrm{c}$.

Таблица 2

Время релаксации избыточной проводимости бинарных смесей $\mathrm{Rb}, \mathrm{Cs} / \mathrm{H}_{2} \mathrm{PO}_{4}$ при $5420 \mathrm{~K}$

\begin{tabular}{|c|c|c|}
\hline Электролит & $\tau_{\mathrm{cp}} \cdot 10^{-4}, \mathrm{c}$ & $\delta, \%$ \\
\hline $\mathrm{RbH}_{2} \mathrm{PO}_{4}$ & 4,85 & 5,0 \\
\hline $0,25 \mathrm{Rb} 0,75 \mathrm{Cs} / \mathrm{H}_{2} \mathrm{PO}_{4}$ & 6,43 & 5,5 \\
\hline $0,5 \mathrm{Rb} 0,5 \mathrm{Cs} / \mathrm{H}_{2} \mathrm{PO}_{4}$ & 9,51 & 6,0 \\
\hline $0,75 \mathrm{Rb} 0,25 \mathrm{Cs} / \mathrm{H}_{2} \mathrm{PO}_{4}$ & 7,25 & 5,5 \\
\hline $\mathrm{Cs} \mathrm{H}_{2} \mathrm{PO}_{4}$ & 4,95 & 5,0 \\
\hline
\end{tabular}

В общем случае следует рассматривать следующие возможные пути увеличения проводимости, часть из которых обсуждены в работае [4]: 1) пробой электролита; 2) появление электронной составляющей проводимости; 3) тепловые эффекты, связанные с ВИР; 4) выделение щелочного металла или протона на катоде; 5) изменение механизма проводимости с дефектного на туннельный (связанное с фазовым переходом); 6) разложение электролита; 7) увеличение концентрации протонных дефектов; 8) рост подвижности носителей заряда.

Об относительно меньшей энергии Н - связи говорит тот экспериментальный факт, что эффект насыщения проводимости для ПТЭ наступает при значительно меньших НЭП по сравнению с другими твердыми электролитами и солевыми расплавами. Этот экспериментальный факт также свидетельствует о небольшой энергии водородной связи в ПТЭ. Таким образом, в ПТЭ и их расплавах в СЭП, вероятно, имеет место частичная или полная ионизация при достижении предельной проводимости (разрыв Н - связей) и образование дополнительных неравновесных носителей заряда, т.е. увеличение концентрации носителей.

Помимо увеличения концентрации протонных дефектов в СЭП возможно возрастание подвижности носителей заряда вследствие снятия эффекта релаксационного торможения, обусловленного ионной атмосферой. В СЭП скорость ионов $\mathrm{H}^{+}$достигает большой величины, так что поляризация решетки ПТЭ не успевает происходить, вследствие чего снимается релаксационное торможение.

Из приведенного выше анализа следует, что рост проводимости твердых электролитов при 
прохождении через них ВИР обусловлен как увеличением подвижности ионов, так и ростом их концентрации с сохранением электролитической природы.

\section{Список литературы:}

1. Багрянцева И.Н. Среднетемпературные протонные проводники на основе смешанных гидросульфатов и дигидрофосфатов щелочных металлов. Диссертация к.х.н., Новосибирск, 2014, $129 \mathrm{c}$.

2. Гаджиев С.M. Предельная электропроводность твердого электролита $\mathrm{CsH}_{2} \mathrm{PO}_{4}$. Национальная ассоциация ученых (НАУ)
Ежемесячный научный журнал. Екатеринбург. №5 (21). 2016. C. 73-76.

3. Гаджиев С.M., Гаджиев А.С. Высоковольтная электропроводность дигидрофосфата рубидия и ее релаксация. Научный журнал «CHRONOS» Мультидисциплинарный сборник научных публикаций. «Вопросы современной науки: проблемы, тенденции и перспективы» Выпуск 11 (37). Москва. 1919. С. 7478.

4. Шабанов О.М., Гаджиев С.М. Эмиссионные спектры и высоковольтная электропроводность расплавленных солей. //Расплавы. -1990. -№ 2. C.49-56. 